\title{
Promoting the Reform of Ideological and Political Course in Colleges and Universities with "Three Self- confidences" as the Guide
}

\author{
Wang Ying \\ Teaching Research Department of Ideological and Political Theory Courses, Jilin Agriculture Science and \\ Technology University
}

Keywords: Three self-confidences; Ideological and political education; Reform; System

\begin{abstract}
Three self-confidences" is a new requirement of the mental status of the whole Party and people of all ethnic groups in the country, as well as the new content of ideological and political education in colleges and universities. Based on the exposition of the teaching significance of "three self-confidence" in ideological and political education in colleges and universities, this thesis promotes the reform of ideological and political courses in colleges and universities with "three self-confidences" as the guide from four aspects of teaching environment, teaching contents, teaching methods and teaching evaluation, and then optimizes the teaching system of ideological and political courses in colleges and universities, thus laying the foundation for guiding and shaping the talents' value concept, ideology, ideals and beliefs and lifestyle in the new era.
\end{abstract}

\section{Introduction}

"Three self-confidences" refers to the confidence in socialist road, theory and system with Chinese characteristics, which is a full affirmation on the practice of socialism with Chinese characteristics since the reform and opening up, a requirement on the mental state of the whole Party and people all over the country in the future development of China, and a basic expectation for China's future talents. In twenty-first century, China has undergone tremendous changes in politics, economy, culture and other aspects, and strong collisions exist between modernity and tradition and between the east and west in values, moral rules and life style, which has exerted a profound impact on the thoughts, consciousness, ideas, ideals and beliefs of college students in the new era and make them present multiple features [1]. This demands to integrate the teaching of "three self-confidences" into the ideological and political course education under the new circumstances and promote the reform of ideological and political courses in colleges and universities with "three self-confidences" as the guide, thus making a contribution to the cultivation of successful successors for socialist construction of China.

\section{The importance of integrating ideological and political education into "three self-confidences"}

Contributing to the improvement of ideological and political accomplishment of college students. Excellent ideological and political accomplishment is one of the necessary requirements for talents in the new era. The "three self-confidences" education can not only corroborate the ideals and beliefs of college students, but also standardize the codes of conduct for college students.

College students are youthful and vibrant and hospitable to new things. They are in the period of formation and consolidation of ideals and beliefs. However, their thoughts are immature in many cases and they lack social experience and are vulnerable to temptations, thus suiting the convenience of the erosion of wrong thinking. Given this, strengthening the "three self-confidences" education in college students can make them realize that adhering to socialism with Chinese characteristics is the only correct way to adhere to scientific socialism in contemporary China. In addition, strict and impartial political discipline is an important component of the ideological and 
political accomplishment of college students, which can standardize the behavior pattern of college students. The strict adherence to political discipline is inherently consistent with the establishment of "three self-confidences". The commitment to "three self-confidences" is the foundation of conscious and strict adherence to political discipline, while the latter is the guarantee for the persistent commitment to "three self-confidences". Therefore, promoting college students to adhere to "three self-confidences" is of important value for them to strictly observe the Party's political discipline.

Contributing to college students' adaptation to the changing social situation. The changing foreign and domestic situations make the ideological and political education for college students face both favorable conditions and severe challenges. With the constant deepening and expanding of opening to the outside world, the in-depth development of socialist market economy and the continuous popularization of the Internet, China's social economic sectors, interest relations and distribution modes show a diversified trend, and people's ideological activities present the characteristics of selectivity, variability and differences, although which will help college students establish self-improvement consciousness, innovation consciousness and sense of talent, some negative effects will be brought about. Some college students have confused political beliefs and obscure ideals and beliefs to varying degrees, and have no confidence in socialism with Chinese characteristics [2]. Through the strengthening of "three self-confidences" education, college students' identity with and confidence in socialist road, theory and system with Chinese characteristics can be enhanced, thus they can adapt to the dynamically changing social situation at home and abroad.

Contributing to college students' long-term development. To achieve long-term development, there must be the road, theory and system for the development, and "three self-confidences" is not only the confidence in socialist road, theory and system with Chinese characteristics, but also a kind of confident mental state. Under the overall mental outlook of "three self-confidences", college students should adhere to the road, theory and system for their own development, in this way, they can identify, bear, let go, see dialectically, speak objectively and do practically in practice, thus comprehensively pursuing the harmonious development between themselves and the society. For contemporary college students, strengthening "three self-confidences" education is of great significance for promoting the integrated development of college students.

"Three self-confidences" education is neither in conflict with the original teaching contents of the ideological and political courses, nor the addition to the courses, instead, "three selfconfidences" education has established the basic ideas and core contents of ideological and political teaching. The education and teaching of ideological and political courses are required to carry on around "three self-confidences", which is the only way to cultivate the talents truly needed by the contemporary Chinese society, and points out the direction for the reform and optimization of the ideological and political course system.

\section{Strategies for ideological and political course reform in colleges and universities with "three self-confidences" as the guide}

Formation of favorable teaching environment. The strengthening of construction of campus culture and the formation of favorable teaching environment of "three self-confidences" play a positive effect in improving the efficiency of ideological and political courses in colleges and universities. The "three self-confidences" education should rely on the construction of campus culture and give optimistic, positive and correct guidance for students' thinking through a rich mixture of cultural activities and community practices [3]. Meanwhile, a great variety of academic activities and knowledge contests should be organized in teaching to stimulate the students' pursuit of scientific and cultural knowledge and encourage them to set up great aspirations and ideals. The blind preaching should be replaced by debates, group discussions and other flexible and receptive forms, and experts and logicians should be regularly invited to hold lectures, thus eliminating the students' resistance psychology towards ideal and belief education, imperceptibly affecting them in the process of research and discussions and enhancing the effectiveness of "three self-confidences" 
education.

Determination of the contents of scientific teaching. The teaching contents of ideological and political courses with "three self-confidences" as the guide should embody the integrity of political theories, the epochal character of ideological contents and the instructional value of ideology. This requires that the deterministic process of teaching contents should not just "repeat what the book says", but carry out integration and reprocessing, namely, to accept or reject, simplify, enrich and perfect the existing teaching contents.

\section{The theoretical education of socialism with Chinese characteristics}

In the "three self-confidences" education, the self-confidence in the theory of socialism with Chinese characteristics is the ideological basis for the self-confidence in the road and system, that is, theory self-confidence demonstrates the rationality of road self-confidence, and interprets the legality of system self-confidence. The crucial link to strengthen college students' "three selfconfidences" is to make the students study well and firmly identify with the theory of socialism with Chinese characteristics. In addition, one of the main learning contents of the theory of socialism with Chinese characteristics is the new ideas, new judgments, new views and new requirements put forward by the new leading organization of the Party center with General Secretary Xi Jinping as the core after the 18th National Congress, including the idea of adhering to socialism with Chinese characteristics is the only road to develop China, the idea of realizing the Chinese dream and the idea of the four-pronged comprehensive strategy of Chinese socialism. These learning contents constitute the new development of Marxism with Chinese features.

\section{National condition education}

It is essential to assist party members among college students to adhere to "three selfconfidences" from the perspective of national condition education, and college students should be made to comprehensively, dialectically learn the national conditions, namely, they should on the one hand see the great achievements that have been made, and on the other hand note the main problems, thus they can realize that there is still a long way to go to realize the Chinese dream, and adhering to "three self-confidences" can provide them with strong mental strength and guarantee of direction.

\section{Education of the history of Chinese Communist Party (CCP)}

The statement of "relay exploration" put forward by the 18th National Congress of the CCP showed that the present road, theory and system are inevitable choices after 90 years of development of Chinese society, as well as the inevitable results of unremitting efforts made by the CCP leading people of all nationalities. In contemporary China, only by adhering to and expanding the road, insisting and enriching the theory, and consolidating and improving the system, will the great rejuvenation of the Chinese nation be realized.

\section{College students' belief education}

The most important thing in one's lifetime is to set up firm ideals and beliefs, which determines a person's life track. "Three self-confidences" education can make college students feel that "three self-confidences" is needed in their own growth and success. The education can also make the students believe that the road of socialism with Chinese characteristics is correct, their brilliant future is based on this road, and their future development depends on the continuous development of this road.

\section{The application of multifarious teaching methods.}

\section{The combination of teachers' guidance and students' initiative}

In the process of strengthening "three self-confidences" education on party members among college students, on the premise of clarifying teaching objectives, teachers act as the guide and students as the subjects to achieve the goal of "cognitive resonance, thinking synchronization, emotional response". Teachers and students make concerted efforts in the interactive process, thus successfully finishing the teaching task [4]. It should be noted that college students are not passive educatees. They are the subjects of education, so special attention should be paid to give full play to their enthusiasm for self-education. When mobilizing college students' enthusiasm for selfeducation, teachers should give full play to their guidance and make students carry out autonomous 
learning and exploration. Through autonomous learning of theories, in-depth social practices, and mutual discussions and debates, college students' learning interest will be stimulated and their correct ideas and beliefs will take shape and be consolidated. In the process of active exploration, college students should be encouraged to study the problems and contradictions encountered in realistic social life and independently explore the correct answers, thus deepening their understanding of Chinese socialism on this basis and further consolidating the "three selfconfidence". In this way, the result will be more significant and lasting than that obtained by simple external indoctrination.

\section{The combination of reasonable teaching and emotional teaching}

The "three self-confidences" education on college students is different from general knowledge education that settles learners' problem of knowledge and ignorance of the learning content and emphasizes the understanding of concepts. "Three self-confidences" education is to solve learners' problem of "to believe and practice the learning content or not", and emphasizes the subjective initiative of learners. Therefore, in addition to mastering relevant knowledge of socialism with Chinese characteristics, the learners should also be allowed to exert subjective initiative and practice. This requires that the "three self-confidences" education on college students should be both reasonable and emotional. It is necessary to carry out reasonable teaching of "three selfconfidences". College students must be educated to grasp relevant knowledge of the formation, development, internal logic and significance of the socialist road, theory and system with Chinese characteristics, so that they can have an abundant theoretical basis. After the students understand and completely accept the knowledge and "principles", special attention should be paid to emotional moving. The contents of "three self-confidences" education should be closely connected to social practice and student learning and living, the major principle should be integrated into practice, and vivid, specific and typical life events can be used to exert influence on college students and cultivate their taste, so that they can resonate in their thoughts and truly feel that Chinese socialism is the choice of history and people and related to the future and hope of the party, the people and the country, thus believing in and adhering to "three self-confidences".

\section{The combination of offline teaching and online teaching}

With the popularity of the Internet, online teaching means such as microblog and WeChat have been prevailing, and the traditional offline teaching means such as blackboard, chalk and classroom importation have been outshone. How to make full use of the rapid message spreading speed, strong participation and interaction and rich interestingness of modern media in the "three selfconfidences" educational teaching activities is an unavoidable problem facing ideological and political course teaching. In view of this, online teaching of ideological and political courses in colleges and universities should be carried out [5]. First, the web blog of "three self-confidences" education should be set up. On the web blog, teachers' study notes and teaching thoughts can be written and articles related to "three self-confidences" can be pushed aperiodically, thus increasing students' information input of "three self-confidences". Second, online video courses of "three selfconfidences" should be set up. The restriction of fixed time and space of traditional classroom teaching can be broken through and the students can freely choose what they want to learn in their spare time. Third, the WeChat interactive platform of "three self-confidences" should be established. The psychological need of college students of being concerned and valued is strong, classroom teaching often cannot meet the need, but WeChat interactive platform just meets it. On the platform, various views of "three self-confidences" confront and argue with each other, which is conductive to mobilizing students' study initiative.

\section{The construction of effective teaching evaluation.}

\section{Establishment of scientific evaluation indexes}

The establishment of scientific evaluation indexes is a basic premise to improve the teaching effect. Firstly, the integrity of the evaluation indexes should be ensured, and the teaching evaluation indexes of "three self-confidences" should be scientifically set up from the aspects of teaching objectives, teaching content, teaching process, teaching methods and students' learning effect. Secondly, the teaching evaluation indexes should be set up and extended according to the specific 
conditions. On the one hand, the evaluation on the contents of "three self-confidences" education should be strengthened, and the proportion of "three self-confidences" teaching evaluation should be improved. On the other hand, the evaluation on the teaching effect of "three self-confidences" should be highlighted, the focus of the evaluation should be put on students' externalization degree on the "three self-confidences" education and attention should be paid to students' performance in extracurricular activities, social practice and daily life [6]. Finally, the establishment of teaching evaluation indexes should lay emphasis on concretization and operability, and turn the abstract evaluation contents into operable items.

\section{The application of multivariate evaluation methods}

The teaching evaluation methods for ideological and political courses include questionnaire method, panel method, lecture attending method and self-inspection method. Each of the teaching evaluation methods has its advantages and disadvantages, so it is very difficult to objectively and fairly evaluate the teaching effect using a single kind of teaching method. Therefore, in order to scientifically evaluate the teaching effect of "three self-confidences", multivariate evaluation methods should be comprehensively used to complement each other's advantages. Firstly, according to the teaching objectives of "three self-confidences", a reasonable teaching evaluation method system should be set up to systematically evaluate the education and teaching process of "three selfconfidences". Secondly, procedural evaluation methods should be explored and used. "Three selfconfidences" education is a dynamic changing process and the students' ideological and political quality and moral quality are also constantly changing, thereinto, there is no lack of qualitative accumulations and qualitative changes. Therefore, procedural evaluation methods should be explored for teaching evaluation on "three self-confidences", and the development and application of evaluation methods such as performance evaluation, non test evaluation and formative evaluation should be strengthened.

\section{Conclusions}

The proposition of "three self-confidences" has pointed out the direction for ideological and political education reform in colleges and universities. In order to improve the teaching effect of "three self-confidences" and cultivate useful talents in the new era, in addition to the abovementioned ideological and political teaching reform strategies, the overall ideological and political teaching system in colleges and universities can be optimized from aspects of compilation of textbooks and special topic teaching.

\section{Acknowledgments}

Project of Jilin provincial leading group of Educational Research: Research on the mode of co construction and sharing of special teaching resources of Ideological and political theory course in Jilin Universities (No: GH13399).

\section{References}

[1] Sun Minghui. Path analysis of strengthening the effectiveness of "three self-confidences" education of ideological and political courses in colleges and universities[J]. Future and Development, 2015, (11): 69-73.

[2]Wu Yanbin, Lu Wenzhong, Peng Tao. Analysis of strengthening the effectiveness of ideological and political theory courses in colleges and universities from the perspective of "three selfconfidences"[J]. School Party Building and Ideological Education, 2016, (2): 29-32.

[3] Ye Kaili. Study of party members of college students adhering to "three self-confidences" based on the survey of four universities in Tianjin. Tianjin Normal University, 2015:37-39.

[4] Chen Zhangcheng, Ning Bo. Research on the innovation and development of ideological and political education in colleges and universities from the perspective of "three self-confidences" [J]. 
School Party Building and Ideological Education, 2014, (8).89-91.

[5] Wang Weiquan, Sun Xu. Promoting teaching innovation of college ideological and political courses with "three self-confidences" education as the core [J]. Journal of Changchun University, 2014, (4): 561-564.

[6] Sun Minghui, Zhou Bo. Analysis of the promotion of teaching evaluation on ideological and political courses in colleges and universities from the perspective of "three self-confidences" [J]. Future and Development, 2016, (9): 99-102. 